\title{
Manejo Clínico das Repercussões do Racismo entre Mulheres que se "Tornaram Negras"
}

\author{
Jeane Saskya Campos Tavares ${ }^{1}$ \\ ${ }^{1}$ Universidade Federal do Recôncavo da Bahia, BA, Brasil. $\quad{ }^{2}$ Universidade Federal do Recôncavo da Bahia, BA, Brasil.
}

Resumo: No Brasil, não há produção sistemática de conhecimentos, métodos ou estratégias para o manejo clínico das repercussões do racismo sobre a saúde mental da população negra. Esta é uma lacuna teórica e prática relevante, pois, quando o terapeuta não reconhece o racismo como produtor de iniquidades sociais, preconceito e discriminação, contribui para aumento de sofrimento psíquico de seu paciente negro e para a manutenção das desigualdades raciais. Neste relato, apresentamos a experiência de atendimento clínico de duas mulheres autodeclaradas negras, universitárias, através de técnicas da Psicoterapia Analítico Funcional (FAP) e Terapia de Aceitação e Compromisso (TAC). Na análise, buscou-se destacar aspectos gerais da condução dos atendimentos que pudessem auxiliar ou suscitar reflexão entre psicólogos de orientações teóricas diversas. O relato de experiência é apresentado em três partes: a) acolhimento e estabelecimento de aliança terapêutica; b) identificação do racismo como origem do sofrimento psíquico; e c) resultados das intervenções. Os principais resultados referem-se ao estabelecimento de vínculo seguro e saudável, ao aumento do repertório de habilidades sociais, à elevação da autoestima e ao desenvolvimento de capacidade de autocompaixão/autocuidado pelas pacientes. Recomenda-se desenvolvimento de sensibilidade e competência cultural entre os profissionais da saúde mental para diminuir as disparidades na quantidade e qualidade do atendimento psicoterápico prestado a esta população.

Palavras-chave: Racismo, Saúde Mental, Análise do Comportamento, Terapia Cognitivo-comportamental, População Negra.

\section{Clinical Management of the Repercussions of Racism among Women who have "Turned Black"}

\begin{abstract}
In Brazil, there is no systematic production of knowledge, methods or strategies for the clinical management of the impact of racism on the mental health of the black population. This is a relevant theoretical and practical gap because when the therapist doesn't recognize racism as a producer of social inequities, prejudice and discrimination, he or she contributes to an increase in the psychological suffering of the black patient and to the maintenance of racial inequalities. In this article, we present the experience of clinical care through Functional Analytic Psychotherapy and Acceptance and Commitment Therapy of two self-declared black, female university students. In the analysis, general aspects of the clinical conduct that could help or elicit reflection among psychologists of diverse theoretical orientations were highlighted. This case report is presented in three parts: a) establishing rapport and the therapeutic alliance, b) identification of racism as a source of psychic suffering and c) results of the therapy. The main results refer to the patients: establishing a safe and healthy bond with their therapist, increasing their repertoire of social skills and self-esteem, and developing their capacity for self-compassion and self-care. It is recommended that the development of cultural sensitivity and cultural competence is established among mental health professionals to improve psychotherapy care offered to the black population.
\end{abstract}

Keywords: Racism, Mental Health, Behavior Analysis, Cognitive Behavioral Therapy, Brazilian Black Population. 


\title{
Manejo Clínico de las Repercusiones del Racismo entre Mujeres que se "Volvieron Negras"
}

\begin{abstract}
Resumen: En Brasil, no hay producción sistemática de conocimientos, métodos o estrategias para el manejo clínico de los efectos del racismo en la salud mental de la población negra. Esta es una laguna teórica y práctica relevante, pues cuando el terapeuta no reconoce el racismo como productor de iniquidades sociales, prejuicio y discriminación, contribuye a un aumento de sufrimiento psíquico de su paciente negro y al mantenimiento de las desigualdades raciales. En este relato, presentamos la experiencia de atención clínica de dos mujeres autodeclaradas negras, universitarias, a través de técnicas de la Psicoterapia Analítico Funcional (FAP) y Terapia de Aceptación y Compromiso (TAC). En el análisis, se buscó destacar aspectos generales de la conducción de los atendimientos que pudieran auxiliar o suscitar reflexión entre psicólogos de orientaciones teóricas diversas. El relato de experiencia se presenta en tres partes: a) acogida y establecimiento de alianza terapéutica; b) identificación del racismo como origen del sufrimiento psíquico; $\mathrm{y}$ c) resultados de las intervenciones. Los principales resultados se refieren al establecimiento de un vínculo seguro y sano, al aumento del repertorio de habilidades sociales, a la elevación de la autoestima y al desarrollo de capacidad de autocompasión/autocuidado por las pacientes.. Se recomienda el desarrollo de sensibilidad y competencia cultural entre los profesionales de la salud mental para disminuir las disparidades en la cantidad y calidad de la atención psicoterápica prestada a esta población.
\end{abstract}

Palabras clave: Racismo, Salud mental, Análisis del comportamiento, Terapia cognitiva-conductual, Población negra.

\section{Introdução}

O racismo consiste na ideologia de que existem raças inferiores a outras, atribuindo a esta crença as desigualdades sociais, culturais, políticas, psicológicas e, portanto, legitimando as diferenças sociais e julgamentos morais entre grupos raciais com base em supostas diferenças biológicas (Zamora, 2012; Schucman, 2014). A despeito da inexistência de fundamento biológico ou genético para distinção entre os diferentes grupos humanos, o termo raça continua sendo utilizado como categoria histórico-social para designar grupos socialmente hierarquizados. Isto porque a categoria raça humana existe no mundo social, prescinde da legitimação científica e media a distribuição desigual de recursos, como o acesso à educação, saúde, habitação, justiça e trabalho (Faro, \& Pereira, 2011; Schucman 2014).

No caso brasileiro, é a cor da pele (e outros traços fenotípicos) que se associa ao conceito de raça biológica da ciência do século XIX. Por esta característica, a utilização do termo raça é mais comum nos estudos brasileiros sobre relações raciais que etnia (associada à cultura e história dos grupos) e, concordando com
Faro e Pereira (2011), é relevante sua utilização, pois o termo etnia pode encobrir o preconceito e o racismo ainda existente.

No Brasil, embora a população negra represente a maioria numérica e tenha vivências específicas de adoecimento que estão intimamente relacionadas aos diversos tipos de racismos (interpessoal, institucional e estrutural), opressão e violência, poucas pesquisas têm sido publicadas sobre a saúde desta população. Para Werneck (2016), não é possível indicar quais as razões para este número baixo de publicações, mas a autora sugere múltiplos fatores como: desinteresse ou falta de estímulo aos pesquisadores, restrições explícitas nas instituições de pesquisa ou barreiras interpostas pelos conselhos editoriais dos periódicos.

Na Psicologia, a produção sobre relações étnico-raciais e preconceito racial é reduzida e concentra-se na Psicologia Social (Martins, Santos, \& Colosso, 2013; Sacco, Couto, \& Koller, 2016), notadamente pelo esforço de psicólogos militantes de movimentos sociais. No campo da psicologia clínica brasileira, não se tem um corpo de conhecimentos, métodos ou estratégias sistematicamente desenvolvidas para o 
manejo clínico das repercussões do racismo sobre a saúde mental da população negra.

A literatura internacional, por sua vez, destaca a necessidade de sensibilidade e competência cultural dos psicólogos, além de adequação da clínica psicológica aos diferentes grupos minoritários que sofrem preconceito e discriminação social em relação a raça, identidade de gênero, orientação sexual, deficiência física, dentre outros. Esta é uma discussão iniciada há mais de quatro décadas, que se relaciona aos direitos humanos e foi institucionalizada através de diretrizes de atuação, como as publicadas pela American Psychology Association (APA) em 2002 e atualizadas em 2017.

No atendimento à população negra, por exemplo, a formação de uma identidade racial é indicada como uma estratégia potente para lidar com o sofrimento psíquico gerado pelo racismo (Jones, \& Neblett, 2016). Meyer, \& Zane (2013) destacam outros aspectos importantes: negros e hispânicos (latinos) manifestam maior necessidade de falar sobre questões raciais nos atendimentos que brancos; a correspondência racial / étnica (quando clientes e provedores de saúde mental compartilham a mesma raça ou etnia) é associada ao aumento da utilização do serviço, desfechos favoráveis ao tratamento, menor abandono do tratamento e maior satisfação; diálogos abertos sobre questões de raça e etnia podem promover um ambiente de confiança que acabará beneficiando o processo de tratamento; o desconhecimento dos terapeutas sobre preconceito e discriminação os impede de avaliar a importância relativa dos vários fatores descritos pelos clientes como relevantes; clientes atendidos por prestadores de cuidados que não reconheciam a realidade de viver em uma sociedade racializada receberam pior qualidade de atendimento.

Esta discrepância entre a literatura nacional e internacional pode ser explicada pelos fatores apontados por Werneck (2016), somados a questões históricas, estruturais, institucionais e específicas do perfil da categoria profissional. E, em relação a esta última, concordamos que: "a grande maioria dos psicólogos e pesquisadores são brancos e socializados entre uma população que se acredita desracializada, o que colabora para reificar a ideia de que quem tem raça é o outro e para manter a branquitude como identidade racial normativa" (Schucman, 2014, p. 84). Neste sentido, Tavares, Oliveira e Lages (2013) discutem como os profissionais tendem a não desenvolver uma per- cepção crítica sobre as relações étnico-raciais e suas implicações no campo da saúde, reproduzindo a ideologia da igualdade social e democracia racial no país e não contribuindo, assim, para com as ações promotoras da equidade. Ao entrevistar psicólogos de três hospitais públicos, identificaram em seus relatos naturalização das desigualdades, viés subjetivista e individualista, além do entendimento da miscigenação como uma saída para a opressão racial e inserção social. Estes mesmos profissionais não sabiam definir racismo institucional, a despeito de conhecerem normas e diretrizes do Sistema Único de Saúde (SUS) sobre equidade em saúde e, embora a ampla maioria da população SUS-dependente seja negra, não sabiam citar doenças ou agravos relacionados a fatores genéticos ou sociais associados aos preconceitos e discriminação contra esta população.

Como questões estruturais e institucionais destacamos que, historicamente, a população negra tem pouco acesso aos serviços privados de saúde, o que contribui para que os profissionais liberais não percebam ou problematizem as especificidades do atendimento clínico a esta população. No sistema público de saúde, o racismo institucional contribui para a iniquidade na assistência prestada a esta população que recebe quantidade menor de atendimentos e de pior qualidade quando comparada à população branca (Werneck, 2016). Na rede de saúde mental, a análise dos indicadores é prejudicada, dentre outros fatores, pela incompletude do quesito raça/cor e a carência de estudos sobre prevalências de transtornos mentais segundo grupos raciais. No entanto, o Ministério da Saúde (Brasil, 2016) informa que a “desproporção entre taxas de internação e taxas de mortalidade em alguns grupos raciais pode significar desigualdades de acesso aos serviços de saúde mental" e, concordando com a literatura, associa o racismo a fatores com ameaças à autoestima, às desigualdades de oportunidades e à violência, "que podem levar a população negra ao sofrimento psíquico, em formas e intensidades diversas" (p. 24).

A busca de artigos nacionais para produção deste relato concentrou-se em publicações entre os anos de 2000 a 2016, disponíveis na biblioteca virtual SciELO e ocorreu entre os meses de junho a agosto de 2017. Como palavras-chave utilizamos, separadamente e combinados entre si, os termos: racismo, psicologia, saúde, saúde mental, sofrimento psíquico, população negra. Identificamos e analisamos três (03) artigos 
nacionais (Alves, Jesus, \& Scholz, 2015; Faro, \& Pereira, 2011; Guimarães, \& Podkameni, 2008) que se referiam especificamente às repercussões do racismo sobre a saúde mental da população negra. O artigo de Guimarães e Podkameni (2008) foi o único a apresentar estratégia de intervenção (Rede de Sustentação Coletiva) que, segundo os autores, pode contribuir para a diminuição dos efeitos nocivos do racismo. Nesta pesquisa-ação, participaram grupos de gestantes negras e não negras de duas comunidades e seguiu-se a abordagem teórico-clínica do psicanalista Donald Winnicott. Nenhum estudo ou relato de atendimento clínico individual descrevendo estratégias culturalmente adequadas para acompanhamento psicoterápico centrado nos efeitos deletérios do racismo sobre a saúde mental da população negra foi localizado.

Apesar das limitações anteriormente apresentadas, registramos avanços no trato das relações raciais na clínica psicológica com a publicação das referências técnicas para atuação de psicólogas(os) com foco nas relações raciais (CFP, 2017), 15 anos após a publicação da Resolução do Conselho Federal de Psicologia no 18/2002. Registramos, ainda, a valiosa contribuição de psicanalistas brasileiras, em particular, da psiquiatra negra Neusa Santos Souza (1983), autora do clássico: Tornar-se negro - As vicissitudes da Identidade do Negro Brasileiro em Ascensão Social. Embora este livro não tenha sido utilizado como base teórica para a elaboração do relato ou nos atendimentos clínicos, tomamos a expressão "tornar-se negro" como metáfora para o processo de reconhecer os diversos tipos de violência proporcionadas pelo racismo e de busca por recriar uma nova identidade enquanto pessoa negra. É, ainda, uma homenagem a esta autora para a qual:

A descoberta de ser negra é mais do que a constatação do óbvio (Aliás, o óbvio é aquela categoria que só aparece enquanto tal. Depois do trabalho de se descortinar muitos véus). Saber-se negra é viver a experiência de ter sido massacrada em sua identidade, confundida em suas perspectivas, submetida a exigências, compelida a expectativas alienadas. Mas é sobretudo, a experiência de comprometer-se a resgatar sua história e recriar-se em suas potencialidades (Souza, 1983, p. 18).

Portanto, considerando a lacuna teórico-prática sobre este tema na Psicologia brasileira, neste relato apresentamos e analisamos a experiência de atendimento clínico de duas mulheres autodeclaradas negras, universitárias, atendidas no Serviço de Psicologia da Universidade Federal do Recôncavo da Bahia, nos quais foram identificadas e manejadas repercussões psicológicas geradas pela experiência de sofrer racismo.

\section{Método}

Foram realizadas sessões semanais, individuais, em consultório, com duração média de 50 minutos. A condução dos casos seguiu a Terapia Analítico Comportamental, utilizando a perspectiva da Psicoterapia Analítico Funcional (Kohlenberg, \& Tsai, 2001) e Terapia de Aceitação e Compromisso (Hayes, Strosahl, \& Wilson, 1999), abordagem adotada pela terapeuta. No entanto, neste relato que a mesma divide com uma terapeuta cognitivo-comportamental, optou-se por destacar aspectos gerais da condução dos atendimentos que possam auxiliar ou suscitar reflexão entre psicólogos de orientações teóricas diversas.

Caso 1- Carolina, 20 anos, 17 sessões. Nas primeiras sessões relatou insegurança, baixa autoestima, ansiedade generalizada, com sensações de taquicardia e sufocamento constantes. Nas primeiras sessões, enfatizou como se sentia "feia", referindo que todas as outras mulheres "são mais bonitas e inteligentes" que ela, regra que a fazia esquivar-se de sair para lugares onde poderia encontrá-las. Estas são descritas como "mulheres brancas, do cabelo liso e bem-arrumadas" (sic). O quesito "bem-arrumadas" referia-se à utilização de roupas e maquiagem seguindo o padrão da moda vigente. Outro aspecto enfatizado por Carolina foi o estabelecimento de relações em que se sentia insegura e desconfiada. Desta forma, todas as suas relações eram descritas como mediadas por falta de intimidade e receio de ser traída, tanto por colegas como pelo namorado.

Caso 2- Tereza, 30 anos, 21 sessões. Relatava humor deprimido, timidez, baixa autoestima, uma não vontade de viver e que "preferia não ter nascido" (sic). Sua vinculação com a família era descrita como conflituosa, marcada por desentendimentos e mágoas. Tereza descrevia episódios frequentes de tristeza, relacionando-os as demandas do seu trabalho, da universidade e aos seus conflitos familiares.

As pacientes autorizaram a publicação desse relato e, para proteger suas identidades, foram utilizados nomes fictícios e dados da história de vida foram 
alterados, sem prejuízo à veracidade do relato sobre a intervenção terapêutica.

\section{Manejo clínico das repercussões do racismo}

Dividimos este relato de experiência em três grandes partes que consistem no acolhimento e estabelecimento de aliança terapêutica, identificação do racismo como origem do sofrimento psíquico e resultados das intervenções. Em cada item serão apresentadas as estratégias, e os objetivos das intervenções serão discutidos, assim como os aspectos que devem ser considerados pelo terapeuta no atendimento a pessoas negras.

\section{Acolhimento e estabelecimento de aliança terapêutica}

Em ambos os casos, o primeiro objetivo terapêutico estabelecido pela psicóloga foi a criação do vínculo. Embora esta meta deva ser alcançada em qualquer relação terapêutica, destacamos que entre as repercussões do racismo destacam-se a dificuldade de estabelecimento de vínculos e a representação de si como inferior, desagradável, inadequado e sensação contínua de não pertencimento, além de percepção do mundo como potencialmente violento (principalmente na relação inter-racial) o que pode influenciar o estabelecimento de vínculo com o terapeuta. Ressaltamos que neste relato a terapeuta tem ascendência asiática o que diminuía as associações raciais negativas, no entanto, devido às características do racismo brasileiro, ela também poderia ser associada à raça branca por beneficiar-se de privilégios raciais.

As duas mulheres diferiam entre si quanto à manifestação de suas desconfianças e dificuldades de vinculação. Carolina apresentava distanciamento afetivo e corporal em relação à terapeuta. Quando questionada, dava respostas curtas, evitava contato visual, apresentava pouca proximidade física e falta de espontaneidade ao manifestar emoções e expressões faciais. Tereza, por sua vez, apresentava expressões corporais e verbais de raiva. Mantinha expressão facial agressiva (especialmente o olhar), mostrava-se rígida na forma de falar, com frases curtas e manifestações corporais que provocavam sentimentos de medo na terapeuta. Desta forma, se Carolina adotava esquiva como estratégia de distanciamento, Tereza impunha o distanciamento de seus interlocutores, promovendo o medo da aproximação.

A despeito dessas diferenças suscitarem afetos distintos na terapeuta, esta seguiu o padrão geral para estabelecimento de vínculos em ambos os casos de acordo com sua orientação teórica. Vale ressaltar que o medo suscitado na terapeuta por Teresa foi diminuindo à medida que a paciente relatava situações as quais se mostrou vulnerável e sensível ao outro, o que não correspondia com os comportamentos não verbais apresentados por ela. Além disso, Tereza descrevia vínculos fortes com amigos e namorado, e grande preocupação e solidariedade à sua família, mesmo com os conflitos vivenciados.

A criação do vínculo entre paciente e terapeuta, base de todo o processo, transforma o setting terapêutico num espaço no qual pacientes podem emitir seus comportamentos-problemas, e o terapeuta pode observá-los diretamente, possibilitando intervenções dentro do espaço clínico, e ampliando formas de fortalecer o repertório comportamental em construção, principalmente, o repertório interpessoal, pois o vínculo se estabelece na interação social, com o desenvolvimento da intimidade e abertura (Kohlenberg, \& Tsai, 2001; Vandenberghe, \& Pereira, 2005).

Nas primeiras sessões com Carolina, tratavam-se assuntos mais triviais, menos relacionados à queixa da insegurança e desconfiança. Eram solicitados relatos sobre atividades ocorridas nos finais de semana, preferências musicais, assuntos preferenciais nos seus estudos. Foi necessário o aumento de verbalizações empáticas por parte da terapeuta e demonstrações explícitas de interesse.

A mesma estratégia foi utilizada com Tereza, mas com menor frequência, pois apresentava mais conteúdos e falava mais que Carolina. À medida que o vínculo entre terapeuta e paciente se formava, Tereza também apresentava maior sensibilidade, com comportamentos de atenção e cuidado à psicóloga. Esta sinalizou a mudança e reforçou a criação de intimidade e abertura na relação, na qual sentia que Tereza podia ser ela mesma. Contudo, mesmo com o desenvolvimento de uma relação íntima, a expressão facial de raiva e o distanciamento de Tereza se mantinham.

Abordar temas triviais contribuía para o contato terapêutico menos ansiogênico e permitia à terapeuta observar respostas genuínas e espontâneas de Carolina ao falar sobre assuntos menos aversivos. Além disso, proporcionava-lhe o contato com o seu pró- 
prio relato, verbalizando suas atividades prazerosas e os sentimentos decorrentes delas, o que funcionava também como modo de aproximá-la da auto-observação e autoconhecimento.

Salientamos que essa estratégia de explorar trivialidades parece ser especialmente indicada para estabelecimento de vínculos e de uma relação empática mútua quando o paciente não refere ou não associa sua baixa autoestima, desesperança e sintomas de ansiedade social ao racismo estrutural, interpessoal e estrutural. Caso a experiência de racismo seja apresentada no início da terapia como fonte de sofrimento, a estratégia de abordar outros assuntos pode ser interpretada como uma forma de desqualificação da sua queixa, o que inviabiliza a continuidade do processo terapêutico. Especial sensibilidade é necessária nesta condução, visto que é comum no cotidiano brasileiro que as referências de pessoas negras à violência racial sejam minimizadas ou não reconhecidas. Da mesma forma, evitar abordar a questão racial na terapia pode ser interpretado como punição, pois é frequente que pessoas negras sejam punidas sem que sejam explicitadas as causas da punição ou inadequação em suas ações.

A partir da sexta sessão, Carolina demonstrou maior confiança na terapeuta, as sessões seguintes pareceram mais reforçadoras para ela e pôde-se conhecer a sua história de vida. Na sétima sessão, Carolina sentiu-se segura para falar sobre suas experiências escolares, sobre a relação com seu pai, também sobre o contexto escolar e familiar, no qual sentiu-se humilhada e julgada por ser negra e pobre. Este foi um momento especialmente relevante no processo terapêutico tanto para Carolina, que expôs um sofrimento profundo à terapeuta quanto para esta profissional que, pela primeira vez, percebeu a associação entre sofrimento psíquico e experiência de racismo. Até então, a terapeuta não havia desenvolvido nenhuma hipótese de que o racismo poderia ser uma variável na sua queixa de insegurança e ansiedade. A partir da apresentação verbal dessa relação, por parte de Carolina, foi preciso reorientar a condução clínica, buscando valorizar a expressão do tema e das suas experiências, ao mesmo tempo em que a terapeuta buscava por literatura específica e pela reflexão acerca de sua postura enquanto pessoa privilegiada racialmente.

O estabelecimento desta relação de confiança só foi possível através da audiência não punitiva pela terapeuta, o que favoreceu a paciente sentir-se segura, livre de julgamentos, comparações e desqualificações. A audiência não punitiva é um tipo de escuta diferenciada "que envolve observação atenta ao que o cliente diz, bem como expressão de respeito e compreensão em relação ao que é dito" (Santos, Santos, \& Marchezini-Cunha, 2012, p. 139). Para Zamignani, Vermes, Meyer e Banaco (2016), é preciso considerar a probabilidade de as queixas apresentadas pelo paciente serem produtos de contingências aversivas, demandando do terapeuta uma atitude compreensiva, sem caráter aversivo ou de julgamento.

\section{Identificação do racismo como gerador de sofrimento psíquico}

Após este momento inicial de acolhimento e vinculação, o terapeuta deve identificar quais as relações estabelecidas pelo paciente entre o sofrimento psíquico e a experiência de racismo relatada. O sucesso desta identificação dependerá do "letramento racial" do terapeuta, que se refere a reeducar o indivíduo em uma perspectiva antirracista (Santos, \& Schucman, 2015), e do momento em que o paciente se encontra em seu processo de "tornar-se negro".

O racismo que gera a autoagressão: a alienação

Mesmo que o fenótipo do paciente corresponda ao de uma pessoa negra ou mesmo que ele se declare negro, é comum que o sofrimento gerado pelo racismo não seja prontamente identificado por aqueles que procuram atendimento psicológico ou pelo profissional de psicologia. Isto se deve, em parte, às características do racismo brasileiro: a) distinção de raças baseada em traços fenotípicos (cor da pele, formato de nariz, lábios e tipo de cabelo) e na origem regional e social (Martins et al., 2013); b) sustentação do mito da democracia racial (estruturante do nacionalismo brasileiro, é a crença na inexistência de conflitos raciais ou impedimento a ascensão social dos negros); e c) ideal de embranquecimento (crença na gradual eliminação do negro, que seria assimilado pela população branca) (Bernardino, 2002). Desta forma, especialmente entre os negros de pele clara, aquele que busca o atendimento pode não se reconhecer como negro, ou não relacionar o racismo às suas crenças disfuncionais, ou ainda não confiar na capacidade do terapeuta de compreender suas questões e manejá-las caso este seja negro.

Dentre os efeitos psicológicos e sociais deste tipo de racismo, destacamos que muitos negros bra- 
sileiros ainda não são conscientes do racismo estrutural ou do estresse crônico a que são submetidos (Faro, \& Pereira, 2011) na experiência cotidiana de discriminação, violências e microagressões. Diante da exposição contínua à violência racial não reconhecida, observamos o desenvolvimento de estratégias compensatórias altamente disfuncionais tendo como exemplo a reprodução de crenças e comportamentos discriminatórios/violentos contra si e seus semelhantes. Estes podem ser ilustrados pela identificação estética e moral com a raça branca, pela defesa de políticas públicas e políticos que apoiam o genocídio da população negra e, por fim, pela dificuldade em reconhecer-se como negro.

Os efeitos do racismo na vida escolar foram narrados em ambos os casos, mas em diferentes fases do desenvolvimento das pacientes. Carolina, que estudava em escola privada, relatou situações de humilhação por colegas brancas, de poder aquisitivo maior que o dela, que sempre ressaltavam seus bens materiais, "seus cabelos lisos e inúmeros namorados" (sic). Estas experiências faziam-na se questionar sobre não poder ter acesso a esses bens ou não poder ser como essas garotas, gerando sentimentos de tristeza e rejeição. Segundo ela, nunca era "escolhida pelos garotos, eles sempre ficavam com as meninas brancas" (sic).

Tereza, por sua vez, referiu com frequência sentimentos de incapacidade e autocobrança em sua experiência como universitária. Reconhecia-se como uma boa aluna, mas os novos desafios da universidade a faziam se sentir incapaz e ansiosa, na busca por bons desempenhos e resultados. Tereza se julgava e autorrecriminava por não conseguir ler todos os textos indicados, por não conseguir notas que considerasse elevadas, por deixar de realizar algumas atividades de estágio ou práticas e por se considerar incapaz ou ter medo de ser julgada pelos colegas e professores.

Ao longo de seis meses de terapia, essas queixas estiveram presentes nas sessões, contudo a história de contingências que levaram Tereza a se sentir insegura e se autocobrar só se revelaram com maior definição para a mesma após esse período. Neste momento, ela expressou que suas exigências quanto ao desempenho acadêmico começaram desde o início da escolarização, quando percebeu que precisava se destacar na sua turma, pois se sentia excluída nesse espaço, por ser diferente, por ser negra.

$\mathrm{Na}$ experiência de Carolina, a violência racial ocorria também no seu contexto familiar através das diversas humilhações dirigidas a ela por seu pai, que lhe chamava de "feia" e "incompetente". O pai de Carolina, descrito como negro por ela, reproduzia comportamentos racistas, como afirmar que "negro não presta", "negro é tudo ladrão" e direcionar duras críticas contra negros que não alisavam os cabelos. À reprodução do racismo, associavam-se o machismo de seu pai, que criava um ambiente aversivo e com excesso de regras, e as traições sofridas por amigos e ex-namorados, que confirmavam e mantinham suas crenças de inadequação e ansiedade social.

Os comportamentos paternos denotavam auto-ódio e poderiam, numa abordagem cognitivo-comportamental, ser compreendidos como estratégias de enfrentamento ou comportamentos compensatórios de esquemas de inadequação, desvalia e desamor. A impossibilidade de o pai reconhecer seu próprio sofrimento como resultado do racismo contribuiu para que Carolina aprendesse a se julgar e a fazer comparações injustas, sentindo-se inadequada por ter cor de pele e tipo de cabelo incompatíveis com a aprovação do seu pai e da sociedade.

Dando toda credibilidade ao seu relato, a terapeuta acolheu Carolina, reafirmando o quanto essas experiências foram violentas e como essas contingências foram cruciais para a produção de baixa autoestima e insegurança. Foi ressaltada a importância de reconhecer o racismo que sofreu/sofre, para compreender e acolher a sua história de vida, entendendo que os comportamentos de que se queixa foram produtos de uma história de violência.

Terapeuta e Carolina conversaram sobre o racismo estrutural, generalizado e institucionalizado, que gerava a insegurança e baixa autoestima de que Carolina se queixava e se julgava em todos os âmbitos da vida. A terapeuta enfatizou como estes relatos de sofrimento por racismo eram importantes para a terapia e como o seu medo de ser julgada ou traída fazia muito sentido diante desta história de contingências aversivas, que se mantinham também no momento presente.

Na sessão seguinte desse relato, a terapeuta perguntou a Carolina como se sentia por ser atendida por uma mulher branca e se ela tinha medo que a mesma pudesse julgá-la ou puni-la. Carolina respondeu que inicialmente teve esse receio, porém acreditava que se fosse um homem branco iria ser muito mais difícil, tornando o gênero da terapeuta um importante fator para a vinculação. Informou, ainda, que ao longo das sessões foi confiando mais 
na psicóloga, sentindo-se acolhida o suficiente para falar do racismo que sofreu/sofre.

Este caso ilustra como o sofrimento não nomeado e/ou não reconhecido pela díade é decisivo para insucesso na aliança terapêutica e das estratégias adotadas pelo terapeuta na condução do processo e de suas intervenções. Neste sentido, o terapeuta pode cometer erros semelhantes aos de casos de luto não reconhecido socialmente ou de vítimas de abusos, em que se desqualifica o sofrimento do paciente ou este sofre nova violência ao ser responsabilizado pelo abuso sofrido.

O terapeuta precisa estar ciente de que, por exemplo, situações de insucesso educacional, profissional ou amoroso, que podem ser atribuídas aos diversos tipos de racismos, tendem a ser interpretadas pela pessoa negra de forma personalista (distorção cognitiva em que pessoa atribui a si a responsabilidade sobre um evento que não está sob o seu controle). Esta distorção é gerada e mantida por crenças sobre si como inadequado, indigno de ser amado, incompetente ou incapaz, associados a sentimentos de auto-ódio, culpa e desesperança, que podem conduzir a um quadro de depressão, com risco de suicídio. Em relação ao mundo e ao futuro, a negação do racismo impede o desenvolvimento da capacidade de interpretação da determinação social dos eventos cotidianos, do senso de controle e de estratégias de enfrentamento eficazes diante da violência racial, que pode ser a base de desenvolvimento de vários transtornos de ansiedade.

Da autoagressão para a heteroagressão: manejando a raiva

No sentido oposto, descobrir-se negro pode incluir um processo de inversão de objeto de medo/ódio, que exige do terapeuta habilidades e competências específicas para proteger a integridade psíquica e física do seu paciente, além de acompanhá-lo num doloroso processo de restruturação de suas crenças e de sua identidade. Se antes a raiva e o desprezo eram direcionados para si e seus semelhantes, ao reconhecer os efeitos nefastos do racismo em sua ancestralidade e na sua vida atual, a pessoa negra poderá redirecionar esses potentes afetos contra as instâncias que simbolizam a opressão racial tais como Estado e seus representantes (indivíduos e instituições) e não negros. O terapeuta deve ter a sensibilidade de acompanhá-lo nesta mudança de foco para que haja um direcionamento que resulte numa vida psíquica e social segura e satisfatória para o seu paciente e sua comunidade, evitando-se o início de um novo processo de desesperança e autodestruição.

Esta experiência guarda semelhanças às relatadas na literatura norte-americana (Kelly, 2006), em que negros americanos dirigem sua raiva contra terapeutas brancos, entendidos como representantes da cultura dominante, e contra familiares por incidentes racistas ocorridos em contatos com parentes. Concordando com Kelly (2006), o uso de exemplos, expressões e metáforas que a princípio pareçam inofensivas à população branca pode ser interpretada como ofensa grave para a população negra. $\mathrm{O}$ terapeuta precisa estar ciente de que neste processo de reconhecimento racial, negras e negros podem se tornar profundamente desconfiados e agressivos em relação às pessoas identificadas como brancas, 0 que é absolutamente justificável diante de gerações de experiências negativas. E esta desconfiança que pode estar associada à perda de oportunidades de autocuidado, à relutância em procurar serviços de saúde mental e à finalização prematura do acompanhamento psicoterápico.

Ainda sobre esta desconfiança, desde o início da psicoterapia Tereza afirmava sua negritude, com especial atenção para o relato de sua transição capilar e aceitação do seu cabelo natural. Porém, somente depois de aproximadamente seis meses de acompanhamento, a mesma conseguiu definir e/ ou verbalizar uma relação entre os sentimentos crônicos de tristeza e o racismo que vinha sofrendo ao longo da sua vida. Ao contrário de Carolina que apresentou a associação entre racismo e sofrimento psíquico na sexta sessão, Tereza necessitou de um tempo mais longo para estabelecer vínculo de confiança com a terapeuta.

A desconfiança e a raiva também influenciaram Tereza ao não realizar uma atividade no estágio por receio de sofrer racismo por parte do público-alvo da atividade: "Eu tive medo de fazer e as senhoras acharem que por ser negra, não seria capaz” (sic). A raiva de Tereza apareceu neste relato e em outros sobre brigas com seu namorado e amigas, pois sentia-se, muitas vezes, incompreendida por essas pessoas, que socialmente brancas, não entendiam sua condição de mulher negra e os preconceitos e regras que lhe foram impostas.

Como intervenção, Tereza foi convidada a conversar com a terapeuta a respeito de como se sentia 
ao ser atendida por uma mulher branca, uma vez que ela relatava raiva e medo de pessoas brancas em relações institucionais e interpessoais. Tereza descreveu que no início da psicoterapia, acreditava que seria muito difícil, mas sentiu-se acolhida pela terapeuta, que cumpriu seu papel em compreender as diferenças e colaborar no processo de autoconhecimento e reconhecimento de si própria. Seguindo os mesmos princípios relatados anteriormente, a condução terapêutica demandou uma audiência não punitiva (Skinner, 2003), que exige do terapeuta uma postura de acolhimento, na qual o relato é reforçado com atenção e interesse pelo terapeuta, sem a emissão de regras e julgamentos.

Durante as sessões, a terapeuta oferecia modelos de vulnerabilidade e expressão de sentimentos, descrevendo como se sentia, principalmente dentro do espaço terapêutico, na relação com Tereza. Este tipo de intervenção foi relevante, pois Tereza apresentava dificuldade de comunicação interpessoal, com destaque para inabilidade de expressar seus sentimentos e mostrar-se vulnerável para os amigos, pois tinha regras rígidas sobre sua necessidade de ser "forte" e "boa" aluna. Desta forma, a terapeuta solicitava descrições sobre os sentimentos e pensamentos de Tereza, que a fizessem entrar em contato com a sua experiência e o seu relato verbal, estando mais sensível a si, e possibilitando a autocompreensão e autocompaixão por seus sentimentos negativos, como tristeza e raiva, entendendo como esses sentimentos foram produtos de contingências ambientais, como o racismo estrutural.

O uso da autorrevelação e a vulnerabilidade relatada pela psicóloga, foram estratégias que colaboraram para o desenvolvimento de uma relação íntima e confiável recíproca. Esta estratégia refere-se à expressão de pensamentos, sentimentos e eventos ocorridos na vida do terapeuta e, principalmente, ocorridos no momento da sessão, onde o comportamento interpessoal do paciente pode ser observado e reforçado (Kohlenberg, \& Tsai, 2001). A revelação do terapeuta permite aprofundar a relação, promover aceitação e empatia de sentimentos e pensamentos desagradáveis por parte do paciente, aumentando a probabilidade de que este se vulnerabilize e expresse seus sentimentos na psicoterapia e em outros ambientes (Moriyama, 2012; Vandenberghe, $\&$ Pereira, 2005) que considere relevantes e seguros, como a família e os amigos.
A fim de produzir sentimentos de autocompaixão e elevação de autoestima, buscou-se a história de contingências de Tereza a qual suas exigências quanto a ser "forte" e "boa" estão vinculadas. Identificaram-se relações que foram produzidas em contextos aversivos, de julgamento, preconceito e exclusão, gerando pensamentos de cobrança e sentimentos de ansiedade, medo e insegurança. Além disso, era provocada a reconhecer suas qualidades, seus interesses, desejos e contextos em que se sentia bem consigo mesma, incentivando que a mesma se expusesse a contingências de reforçamento positivo, que possibilitassem a produção de sentimentos de autoestima (Guilhardi, 2002).

O terapeuta deve estar, portanto, disponível para lidar com os sentimentos de raiva e ressentimento, assim como acolher uma visão de mundo mediada pela dor da opressão sem ceder à tendência a interpretar equivocadamente essas visões de mundo como distorção cognitiva, paranoia, autopiedade ou falta de motivação. É necessário compreender que a pessoa negra pode apresentar comportamentos ambíguos como a necessidade de aderir a determinados grupos sociais (religiosos e/ou políticos) que lhe proporcionem senso de pertencimento e permitam-na construir uma nova identidade. Simultaneamente, a despeito da descoberta de um novo tipo de beleza, força e poder, esta mesma pessoa pode apresentar sérias dificuldades de planejamento do futuro, uma vez que este lhe parece incerto devido a suas experiências com o racismo. Assim como pode desejar afastar-se dos grupos e da discussão sobre racismo numa tentativa de experimentar o privilégio branco de não ter sua existência racializada (Schucman, 2014).

\section{Resultados terapêuticos: da heteroagressão para o autocuidado e a autocompaixão}

Os principais resultados que destacamos neste relato referem-se à experiência de estabelecimento de vínculo seguro e saudável, o aumento do repertório de habilidades sociais, elevação da autoestima e desenvolvimento de capacidade de autocompaixão/ autocuidado em Carolina e Tereza.

Compaixão é um termo utilizado por Tsai et al. (2011), entendido como um sentimento de amor e reciprocidade, que pode ser desenvolvido através da relação terapêutica. A utilização do termo tem ocorrido com maior frequência no âmbito da Terapia de 
Aceitação e Compromisso, sendo estudada com maior profundidade por Neff (2003a) e Gilbert (2014), que conceituam a compaixão como um sentimento de abertura ao sofrimento do outro, reconhecendo, sem julgamentos, a experiência de dor do outro. Nesse sentido, a autocompaixão envolveria tais posturas para consigo próprio, fazendo o indivíduo olhar e cuidar do seu sofrimento, validando suas experiências negativas ou positivas sem julgamentos ou exigências (Neff, 2003b).

O estabelecimento da relação terapêutica e o aumento do repertório de habilidades sociais favoreceram a ampliação do repertório verbal, de comportamentos assertivos e de uma relação íntima e profunda na psicoterapia. Esse processo também objetivou o fortalecimento de comportamentos que pudessem ampliar os sentimentos de autoestima que, segundo Guilhardi (2002), é produto de contingências de reforçamento positivo, tendo um caráter eminentemente social e desenvolvido ao longo da sua história de vida. Para tal, foram produzidas contingências reforçadoras ao incentiva-las a participar de atividades que lhes davam prazer, como por exemplo, participar de grupos de pesquisa e extensão universitárias, estudar mais temas relacionados a mulher negra e saúde. $\mathrm{Na}$ dimensão social, foram incentivadas a se divertir mais com os amigos, colegas da faculdade e de outros contextos que participavam, bem como serem mais assertivas em suas relações interpessoais.

Em relação à Carolina o ambiente universitário era percebido como muito reforçador e contribuía para que esta se sentisse mais aceita e feliz consigo mesma. Afirmava se sentir segura nesse espaço e capaz de lutar pela causa da mulher negra, o que representou uma excelente estratégia de produção de autoestima e socialização. Relatava, ao final do processo, menos episódios de ciúmes e desconfiança com namorado e amigos, expressando sentimentos de aceitação e autoconfiança.

Ao final do processo psicoterapêutico, Tereza já relatava mais compaixão consigo mesma, avaliava-se com um ótimo nível de autoconhecimento e reconhecimento de suas potencialidades e interesses. Descreveu que "a psicoterapia foi um processo de renascimento", trazendo mudanças "no meu olhar para mim mesma" (sic). Conseguia expressar e comunicar de forma mais assertiva seus sentimentos, tornando seus vínculos com amigos e colegas ainda mais fortes. Através do desenvolvimento de comportamentos de autocuidado e valorização de si, encontrou um caminho possível para ampliar sua inserção em contextos que produziam mais sentimentos de autoestima.

A compreensão da sua história de vida, desenvolvimento de autoconhecimento e repertório verbal quanto aos seus sentimentos, em conjunto com a produção de contingências que favoreceram a autoestima foram preponderantes para Tereza se sensibilizar quanto aos comportamentos que lhe faziam esquivar-se das experiências cotidianas, e que lhe mantinham em um contexto de insegurança e medo. Nesse processo, pôde verbalizar o sofrimento que passou/passa por ser negra, além de sentir-se validada e acolhida por conviver com sentimentos tão doloridos, bem como buscar estratégias funcionais para lidar com o racismo estrutural. Tereza percebeu que sua excessiva autoexigência na busca por ser "boa" e "forte" não era uma busca para si própria, mas uma reafirmação social de que era capaz. Considerou que talvez não precisasse mais fazer isso pelos outros e sim por si mesma, exercitando a autocompaixão e autoaceitação.

\section{Considerações finais}

Neste artigo, buscamos indicar possibilidades e suscitar questões relacionadas ao atendimento clínico oferecido à população negra brasileira e contribuir para uma melhor compreensão na psicologia clínica acerca das especificidades desta população. Neste breve relato, pode-se perceber que a falta de sensibilidade cultural (habilidade de compreender e aprender sobre pessoas cuja formação cultural é diferente) e de competência cultural (estar adequadamente preparado ou qualificado) entre os profissionais da saúde mental pode causar disparidades na quantidade e qualidade do atendimento psicoterápico prestado a esta população.

A fim de demonstrar possibilidades de reorientação das práticas clínicas destinadas a esta população, destacamos que a terapeuta se empenhou em adequar suas intervenções e rever seu posicionamento social e subjetivo ao ser sensibilizada pelo sofrimento de Carolina e Tereza. Neste percurso, validava e apoiava os sentimentos de insegurança, tristeza e raiva das mesmas, a medida em que reconhecia e aceitava seus próprios anseios e medos em conduzir uma questão tão pouco debatida na psicologia clínica e no seu contexto social. O desenvolvimento da relação terapêutica mudou ambas (paciente-psicóloga), num 
processo em que Carolina e Tereza permitiram-se ser elas mesmas, criando uma relação autêntica e modificadora, redefinindo a forma como estas se percebem e como a terapeuta percebe a si mesma, enquanto psicóloga e cidadã.

Este texto pretendeu ser, ainda, um convite à revisão das crenças disfuncionais e discriminatórias dos psicólogos clínicos acerca da baixa adesão ou "dificuldades de compreensão" de pessoas pobres/de baixa escolaridade/negras brasileiras aos procedimentos e teorias eurocentrados/estadunidenses desenvolvidos historicamente para populações brancas e classe média. Neste sentido, os terapeutas brasileiros precisam refletir acerca de seus privilégios raciais e como contribuem ou não para manutenção da violência racial, para que possam cuidar de grupos raciais não hegemônicos, assim como desenvolver abordagens culturalmente adequadas a estas populações.

\section{Referências}

Alves, M. C., Jesus, J. P., \& Scholz, D. (2015). Paradigma da afrocentricidade e uma nova concepção de humanidade em saúde coletiva: Reflexões sobre a relação entre saúde mental e racismo. Saúde em Debate, 39(106), 869-880. https://doi.org/10.1590/0103-1104201510600030025

American Psychological Association - APA. (2017). Multicultural guidelines: An ecological approach to context, identity, and intersectionality. Washington, DC: o autor. Recuperado de http://www.apa.org/about/policy/multicultural-guidelines.pdf

Bernardino, J. (2002). Ação afirmativa e a rediscussão do mito da democracia racial no Brasil. Estudos Afro-Asiáticos, 24(2), 247-273. https://doi.org/10.1590/S0101-546X2002000200002

Brasil. Ministério da Saúde. (2016). Painel de indicadores do SUS no 10: Temático saúde da população negra Vol. VII. Brasília, DF: o autor.

Conselho Federal de Psicologia - CFP. (2017). Relações raciais: Referências técnicas para atuação de psicólogas/os. Brasília, DF: o autor.

Faro, A., \& Pereira, M. E. (2011). Raça, racismo e saúde: A desigualdade social da distribuição do estresse. Estudos de Psicologia, 16(3), 271-278. https://doi.org/10.1590/S1413-294X2011000300009

Gilbert, P. (2014). The origins and nature of compassion focused therapy: PsychSource. British Journal of Clinical Psychology, 53(1), 6-41. https://doi.org/10.1111/bjc.12043

Guilhardi, H. J. (2002). Auto-estima, autoconfiança e responsabilidade. In: M. Z. S. Brandão, F. C. S. Conte, \& S. M. B. Mezzaroba (Orgs.), Comportamento humano: Tudo (ou quase tudo) que você precisa saber para viver melhor (pp. 63-98). Santo André, SP: ESETec.

Guimarães, M. A. C., \& Podkameni, A. B. (2008). A rede de sustentação coletiva, espaço potencial e resgate identitário: Projeto mãe-criadeira. Saúde e Sociedade, 17(1), 117-130. https:// doi.org/10.1590/S0104-12902008000100011

Hayes, S. C., Strosahl, K., \& Wilson, K. G. (1999). Acceptance and commitment therapy: An experiential approach to behavior change. New York, NY: Guilford.

Jones, S. C. T., \& Neblett, E. W. (2016). Future directions in research on racism-related stress and racial-ethnic protective factors for black youth. Journal of Clinical Child \& Adolescent Psychology, 46(5), 754-766. https://doi.org/ 10.1080/15374416.2016.1146991

Kelly, S. (2006). Cognitive-behavior therapy with african americans. In: P.A. Hays, \& G. Y. Iwamasa (Orgs.), Culturally responsive cognitive-behavioral therapy: Assessment, practice, and supervision (pp. 97-116). Washington, DC: American Psychological Association.

Kohlenberg, R. J., \& Tsai, M. (2001). Psicoterapia analítica funcional: Criando relações terapêuticas intensas e curativas (F. Conte, M. Delliti, M. Z. Brandão, P. R. Derdyk, R. R. Kerbauy, R. C. Wielenska et al., trads.). Santo André, SP: ESETEc. (Obra original publicada em 1991).

Martins, E., Santos, A. O., \& Colosso, M. (2013). Relações étnico-raciais e psicologia: Publicações em periódicos da SciELO e Lilacs. Psicologia: Teoria e Prática, 15(3), 118-133.

Meyer, O. L., \& Zane, N. (2013). The influence of race and ethnicity in clients' experiences of mental health treatment. Journal of Community Psychology, 41(7): 884-901. https://doi.org/10.1002/jcop.21580. 
Moriyama, J. S. (2012). Revelações do terapeuta como estratégia de intervenção: Descrição de um caso clínico. In: S. R. Souza, \& V. B. Haydu (Orgs.), Psicologia comportamental aplicada: Avaliação e intervenção nas áreas da saúde, da clínica, da educação e do esporte (pp.143-157, 2a ed.). Londrina, PR: Universidade Estadual de Londrina.

Neff, K. D. (2003a). The development and validation of a scale to measure self-compassion. Self and Identity, 2(3), 223-250. https://doi.org/10.1080/15298860309027

Neff, K. D. (2003b). Self-compassion: An alternative conceptualization of a healthy attitude toward oneself. Selfand Identity, 2(2), 85-102. https:// doi.org/10.1080/15298860309032

Resolução CFP № 018/2002. Estabelece normas de atuação para os psicólogos em relação ao preconceito $e$ à discriminação racial. Recuperado de https://site.cfp.org.br/wp-content/uploads/2002/12/resolucao2002_18.PDF

Sacco, A. M., Couto, M. C. P. P., \& Koller, S. H. (2016). Revisão sistemática de estudos da psicologia brasileira sobre preconceito racial. Temas em Psicologia, 24(1), 233-250. https://doi.org/10.9788/TP2016.1-16

Santos, A. O., \& Schucman, L. V. (2015). Desigualdade, relações raciais e a formação de psicólogo(as). Revista EPOS, 6(2), 117-140.

Santos, G. M., Santos, M. R., \& Marchezini-Cunha, V. (2012). A escuta cautelosa nos encontros iniciais: A importância do clínico analítico-comportamental ficar sob controle das nuances do comportamento verbal. In: N. B. Borges, \& F. A. Cassas (Orgs.), Clínica analítico comportamental: Aspectos teóricos e práticos (pp. 138-146). Porto Alegre, RS: Artmed.

Schucman, L. V. (2014). Sim, nós somos racistas: Estudo psicossocial da branquitude paulistana. Psicologia \& Sociedade, 26(1), 83-94. https://doi.org/10.1590/S0102-71822014000100010

Skinner, B. F. (2003). Ciência e comportamento humano (J. C. Todorov, \& R. Azzi, trads., 11a ed.). São Paulo, SP: Martins Fontes. (Obra original publicada em 1953).

Souza, N. S. (1983). Tornar-se negro: As vicissitudes da identidade do negro brasileiro em ascensão social. Rio de Janeiro, RJ: Graal.

Tavares, N. O., Oliveira, L. V., \& Lages, S. R. C. (2013). A percepção dos psicólogos sobre o racismo institucional na saúde pública. Saúde em Debate, 37(99), 580-587. https://doi.org/10.1590/S0103-11042013000400005

Tsai, M., Kohlenberg, R. J., Kanter, J. W., Kohlenberg, B., Follete, W. C., \& Callaghan, G. M. (2011). Um guia para a psicoterapia analítica functional (FAP): Consciência, coragem, amor e behaviorismo (F. Conte, \& M. Z. Brandão, trads.). Santo André, SP: ESETEc. (Obra original publicada em 2009).

Vandenberghe, L. \& Pereira, M. B. (2005). O papel da intimidade na relação terapêutica: uma revisão teórica à luz da análise clínica do comportamento. Psicologia: Teoria e Prática, 7(1), 127-136.

Werneck, J. (2016). Racismo institucional e saúde da população negra. Saúde e Sociedade, 25(3), 535-549. https://doi.org/10.1590/s0104-129020162610

Zamignani, D. R., Vermes, J. S., Meyer, S. B. \& Banaco, R. A. (2016). Terapia analítico -comportamental. In: Rodrigues Júnior, O. M. (Org.), Práticas das psicologias comportamentais no Brasil (pp. 51-69). São Paulo, SP: Instituto Paulista de Sexualidade.

Zamora, M. H. R. N. (2012). Desigualdade racial, racismo e seus efeitos. Fractal: Revista de Psicologia, 24(3), 563-578. https://dx.doi.org/10.1590/S1984-02922012000300009

Jeane Saskya Campos Tavares

Psicóloga pela Universidade Federal da Bahia (UFBA). Docente da Universidade Federal do Recôncavo da Bahia (UFRB). Doutora em Saúde Pública pelo Instituto de Saúde Coletiva da Universidade Federal da Bahia (ISC/UFBA). Salvador - BA. Brasil

E-mail: jeanetavares@hotmail.com

http://orcid.org/0000-0001-5745-1417 


\section{Sayuri Miranda de Andrade Kuratani}

Psicóloga. Mestra pelo Instituto de Humanidades, Artes e Ciências (IHAC) da Universidade Federal da Bahia. Psicóloga técnica do Serviço de Psicologia da Universidade Federal do Recôncavo da Bahia. Santo Antônio de Jesus - BA. Brasil.

E-mail: sayurikuratani@gmail.com

(iD) http://orcid.org/0000-0001-6778-7563

Recebido $30 / 08 / 2017$

Aceito 23/08/2018

Received 08/30/2017

Approved 08/23/2018

Recibido 30/08/2017

Aceptado 23/08/2018

Como citar:Tavares, J.S.C. \& Kuratani, S.M.A. (2019). Manejo Clínico das Repercussões do Racismo entre Mulheres que se “Tornaram Negras”. Psicologia: Ciência e Profissão, v.39, e184764, 1-13.

https://doi.org/10.1590/1982-3703003184764

How to cite: Tavares, J.S.C. \& Kuratani, S.M.A. (2019). Clinical Management of the Repercussions of Racism among Women who have "Turned Black”. Psicologia: Ciência e Profissão, v.39, e184764, 1-13. https://doi.org/10.1590/1982-3703003184764

Cómo citar:Tavares, J.S.C. \& Kuratani, S.M.A. (2019). Manejo Clínico de las Repercusiones del Racismo entre Mujeres que se “Volvieron Negras”. Psicologia: Ciência e Profissão, v.39, e184764, 1-13. https://doi.org/10.1590/1982-3703003184764 